\title{
SINTAXE DAS ORAÇÕES COMPLEXAS EM PORTUGUÊS: UMA PROPOSTA DE DESCRIÇÃO E ENSINO
}

\author{
Ana Carolina SPERANÇA-CRISCUOLO*
}

- RESUMO: Neste trabalho, a partir de uma discussão acerca de problemas relacionados ao ensino de gramática, pretende-se fazer uma proposta de descrição e ensino de algumas orações subordinadas substantivas sob uma perspectiva interdiscursiva. Com base nos pressupostos da teoria da Gramática Discursivo-Funcional (HENGEVELD; MACKENZIE, 2008), observaram-se aspectos subjetivos codificados na sintaxe dessas orações, motivados pelas intenções do falante. Verificou-se que as construções complexas estudadas, do ponto de vista pragmático, compreendem estratégias de que o falante dispõe para demonstrar maior ou menor comprometimento com o que diz, preservando sua face, e também para garantir a confiabilidade da informação asseverada; do ponto de vista do sistema da língua, revelam adaptações que a língua sofre em função das necessidades comunicativas do falante (BYBEE, 2010). Acredita-se que o ensino dessas orações, a partir de sua funcionalidade, pode tornar a prática em sala de aula mais eficiente, melhorando o desempenho linguístico dos alunos.

- PALAVRAS-CHAVE: Sintaxe. Oração complexa. Abordagem funcionalista. Complexidade. Descrição. Ensino.

\section{Considerações iniciais}

O ensino de gramática, em geral, sempre se apoiou em obras inspiradas na tradição gramatical iniciada com os gregos e propagada durante séculos através dos manuais. O mesmo procedimento das primeiras investigações linguísticas - observação de paradigmas, descrição formal dos elementos e classificação - foi aplicado ao ensino da língua, ao que se deve o forte apego à nomenclatura gramatical e o caráter formalista do ensino dessa disciplina, particularmente. No entanto, com o advento da Linguística Moderna e o desenvolvimento de diferentes teorias que passaram a observar também os aspectos extralinguísticos que motivam a organização do sistema, foi possível constatar a natureza heterogênea da linguagem e a necessidade de se considerar, na análise linguística, o contexto comunicativo, os participantes da interação, suas intenções, entre outros aspectos. Em termos epistemológicos, é possível dizer que a noção de língua/linguagem que se passou a ter, especialmente a

* UNESP - Universidade Estadual Paulista. Faculdade de Ciências e Letras - Departamento de Lingüística. Araraquara - SP - Brasil. 14800-901 - carolinasperanca@yahoo.com.br 
partir da segunda metade do século XX, possibilitou descrições ${ }^{1}$ mais completas e aprofundadas da língua, vista como um instrumento comunicativo e não como um sistema fechado e independente.

No que diz respeito ao contexto de ensino, por outro lado, acredita-se que houve um desencontro entre as novas abordagens da língua e a prática efetiva em sala de aula. Até a década de 50, considerando-se o ensino de Língua Portuguesa no Brasil, a escola era acessível apenas à elite, que já possuía certo domínio da norma culta padrão (tendo em vista que desde muito cedo adquiria o hábito da leitura), cabendo à escola apenas o ensino da norma gramatical, baseado nos manuais de gramática tradicional. Contudo, a democratização do ensino nessa época fez com que um público muito variado tivesse acesso à escola, o que passou a revelar as falhas das abordagens pedagógicas de até então (GERALDI, 1993). O baixo desempenho linguístico dos alunos fez com que muitos estudiosos, por volta da década de 80, começassem a questionar problemas relacionados ao ensino da língua, e uma das grandes causas - talvez a maior - foi atribuída ao ensino da gramática.

A partir da proposta de novas teorias linguísticas (Análise do Discurso, Linguística Textual, Sociolinguística, dentre outras), foram criados os Parâmetros Curriculares Nacionais (BRASIL, 1997, 1998), com a finalidade de reorientar o ensino da língua. O foco deixou de ser a gramática e passou a ser a produção e compreensão de textos a partir do estudo dos diversos gêneros textuais, dos mecanismos de coesão e coerência, das características dos contextos de produção dos enunciados. Migrou-se de um extremo a outro: do ensino da gramática por si mesma para o trabalho com texto/contexto, desconsiderandose que o texto é construído também pela gramática. Mesmo assim, o resultado das avaliações de desempenho linguístico dos alunos continua insatisfatório, conforme se pode observar pelos dados oficiais do ENEM, desde sua primeira edição em $1999^{2}$.

Com base nessas considerações, acredita-se que o problema não está no ensino da gramática, propriamente, mas na maneira como ele se dá. Abordar a gramática dissociada do uso, com a finalidade de classificar os elementos linguísticos, de fato, não garante o desenvolvimento do aluno em termos de competência linguística. Por outro lado, não se pode negar que a gramática (enquanto um conjunto de propriedades fonológicas, lexicais e sintáticas da língua, e não como regras prescritivas) está na base de qualquer atividade de uso da linguagem, promovendo a materialização do texto. Considerar a gramática a partir da interação entre os usuários é procurar compreender de que maneira

Fala-se em "descrições" considerando-se as diversas linhas teóricas dentro da Linguística.

Informações disponíveis em: <http://www.inep.gov.br> 
a organização dos elementos linguísticos reflete as intenções do falante e, sob essa perspectiva, a gramática deve ser vista como uma ferramenta para resolver possíveis problemas de comunicação. Daí a importância do seu ensino.

Neste trabalho, que tem como foco a sintaxe das orações complexas do português, propõe-se uma descrição de algumas orações subordinadas substantivas a partir de uma perspectiva interdiscursiva ${ }^{3}$. Pode-se dizer que as construções complexas são de grande importância na arquitetura do texto, mostrando-se um padrão de uso bastante recorrente e produtivo na língua portuguesa. Na análise do corpus ${ }^{4}$, apareceram com maior frequência as orações substantivas Objetivas Diretas (OSSOD) e as Subjetivas (OSSS), conforme mostra a Tabela 1:

Tabela 1 - Orações subordinadas substantivas no corpus

\begin{tabular}{l|c|c|c|c|c|c|c}
\hline \multicolumn{1}{c|}{ Corpus } & Total & OSSOD & OSSS & OSSCN & OSSP & OSSOI & OSSA $^{\mathbf{5}}$ \\
\hline \multicolumn{1}{c}{ Tipo narrativo } & 213 & 168 & 10 & 17 & 14 & 2 & 2 \\
\begin{tabular}{l} 
Notícia \\
\hline Conto/romance
\end{tabular} & 248 & 145 & 32 & 24 & 28 & 16 & 3 \\
\hline \multicolumn{1}{c}{ Tipo argumentativo } & & & & & & & \\
Artigo de opinião & 243 & 105 & 51 & 44 & 17 & 21 & 5 \\
\hline $\begin{array}{l}\text { Artigo de divulgação } \\
\text { científica }\end{array}$ & 275 & 151 & 58 & 19 & 33 & 8 & 6 \\
\hline \begin{tabular}{l} 
Total \\
\hline
\end{tabular} & $\mathbf{9 7 9}$ & $\mathbf{5 6 9}$ & $\mathbf{1 5 1}$ & $\mathbf{1 0 4}$ & $\mathbf{9 2}$ & $\mathbf{4 7}$ & $\mathbf{1 6}$ \\
\hline
\end{tabular}

Fonte: Elaboração própria.

3 Neste trabalho, o termo "interdiscursivo" refere-se à língua em uso, a partir da interação entre os falantes. Tal esclarecimento é relevante por se tratar, também, de um termo-chave na teoria da Análise do Discurso de linha francesa.

4 O corpus é composto por:

(1) Textos jornalísticos: notícias e artigos de opinião dos jornais Folha de S. Paulo e O Estado de S. Paulo.

(2) Textos literários: contos de Lygia Fagundes Telles e Carlos Drummond de Andrade, e os romances Dom Casmurro e Vidas Secas.

(3) Textos de divulgação científica: revistas Superinteressante e Galileu.

5 OSSOD: Oração Subordinada Substantiva Objetiva Direta

OSSS: Oração Subordinada Substantiva Subjetiva

OSSCN: Oração Subordinada Substantiva Completiva Nominal

OSSP: Oração Subordinada Substantiva Predicativa

OSSOI: Oração Subordinada Substantiva Objetiva Indireta

OSSA: Oração Subordinada Substantiva Apositiva 
Dentre os dois tipos de orações subordinadas substantivas predominantes no corpus, realizou-se um recorte a partir dos predicadores mais frequentes: no caso das Objetivas Diretas, verbos dicendi e verbos de atividade mental; no caso das Subjetivas, a construção "ser + adjetivo", como apresentado na Tabela 2:

Tabela 2: Predicadores mais frequentes na Oração Principal (OP)

\begin{tabular}{l|c|c|c}
\hline \multicolumn{1}{c|}{ Corpus } & $\begin{array}{c}\text { Predicador OP } \\
\text { Verbo dicendi } \\
\text { (OSSOD) }\end{array}$ & $\begin{array}{c}\text { Predicador OP } \\
\text { Verbo atividade } \\
\text { mental } \\
\text { (OSSOD) }\end{array}$ & $\begin{array}{c}\text { Predicador OP } \\
\text { "ser + adjetivo" } \\
\text { (OSSS) }\end{array}$ \\
\hline \multicolumn{1}{c|}{ Tipo narrativo } & $130 / 168$ & $12 / 168$ & $4 / 10$ \\
Notícia & $48 / 145$ & $36 / 145$ & $23 / 32$ \\
\hline Conto/romance & $44 / 105$ & $19 / 105$ & $31 / 51$ \\
\hline \multicolumn{1}{c|}{ Tipo argumentativo } & $60 / 151$ & $44 / 151$ & $44 / 58$ \\
Artigo de opinião & $\mathbf{2 8 2 / 5 6 9}$ & $\mathbf{1 1 1 / 5 6 9}$ & $\mathbf{1 0 2 / 1 5 1}$ \\
\hline $\begin{array}{l}\text { Artigo de divulgação } \\
\text { científica }\end{array}$ & \multicolumn{2}{|}{} \\
\hline Total & & & \\
\hline
\end{tabular}

Fonte: Elaboração própria.

Procurou-se observar de que maneira aspectos pragmáticos interferem na organização dessas construções, em diferentes contextos de uso, e que funcionalidade elas assumem na interação entre falante e ouvinte. Espera-se que os resultados obtidos e a discussão aqui proposta possam oferecer sugestões para uma possível mudança da prática pedagógica associada ao ensino de sintaxe e também da gramática, de um modo geral.

\section{Situação atual do ensino de sintaxe: divórcio entre a descrição gramatical e a prática de escrever/entender o texto}

Embora as bases dos PCNs (BRASIL, 1997, 1998) se assentem numa abordagem bastante inovadora no que diz respeito ao ensino da gramática, defendendo que este se dê a partir do uso que os falantes fazem da língua em quaisquer de suas modalidades, o que se verifica em manuais e livros didáticos que servem de base ao ensino atualmente são exercícios que muito se assemelham à abordagem 
tradicional da gramática. No que diz respeito às orações complexas, o objetivo das atividades ainda é a identificação da função sintática que a oração subordinada exerce em relação à oração principal do período composto. Embora se encontre um grande número de textos autênticos e variados nestes materiais (que de fato ofereceriam a oportunidade de um trabalho diferente em sala de aula), a natureza da descrição gramatical se revela desvinculada dos propósitos comunicativos, permanecendo no nível da forma e não se atentando à funcionalidade que esta assume no contexto em que ocorre.

Considerar a língua a partir da função que seus elementos assumem em um determinado contexto significa observar de que maneira as intenções do falante se codificam no texto. Segundo Hengeveld e Mackenzie (2008), o falante parte de uma intenção comunicativa para então produzir seus enunciados, o que acompanha a própria lógica de uso da língua. Acredita-se que, a partir do momento em que o aluno for capaz de identificar as intenções de seu interlocutor com base em "pistas" presentes no texto, será também capaz de expressar suas intenções de maneira satisfatória, com a produção de bons textos. Infelizmente, o que se verifica atualmente é uma grande dificuldade, por parte dos alunos, tanto na compreensão quanto na produção de textos, o que confirma a necessidade de uma mudança na prática com a linguagem em sala de aula.

É importante ressaltar que todos os aspectos da língua (morfossintáticos, semânticos, pragmáticos e discursivos) devem ser trabalhados em conjunto, partindo-se da funcionalidade das expressões linguísticas para a observação de sua organização. Não se pretende, neste artigo, descrever as orações subordinadas estudadas de acordo com a nomenclatura proposta na Gramática DiscursivoFuncional (HENGEVELD; MACKENZIE, 2008), tendo em vista a finalidade pedagógica da discussão que aqui se faz. Contudo, os pressupostos da teoria no que diz respeito ao tratamento da gramática revelam-se de grande pertinência para uma abordagem pautada no uso da língua.

\section{Ponto de vista teórico: sintaxe como eixo da textualidade em situação interdiscursiva}

Considerar as expressões linguísticas a partir da situação comunicativa em que são utilizadas caracteriza uma abordagem funcionalista a língua, em que a sintaxe é considerada instrumental em relação à semântica, e esta, instrumental em relação à pragmática (DIK, 1989). Dessa maneira, todos os níveis de análise linguística são relevantes para a descrição do funcionamento linguístico. Segundo Dik (1997, p.409, tradução nossa), 
ULNs [usuários de uma língua natural] não falam por sentenças isoladas ou orações isoladas, mas as combinam em dimensões mais extensas e complexas para as quais podemos usar o termo geral "discurso". Um discurso é mais (muito mais) que uma sequência arbitrária de orações. Portanto, ainda que tivéssemos uma teoria otimizada da oração, essa teoria deixaria muito a desejar quando considerada um componente de uma teoria mais ampla da competência comunicativa dos ULNs. Além disso, uma vez que orações, em sua estrutura interna, são sensíveis a uma variedade de fatores discursivos, uma teoria "otimizada" da oração (isolada) é simplesmente impossível. ${ }^{6}$

Apesar de a Gramática Funcional (GF) proposta por Dik ter como objetivo a descrição da estrutura subjacente da oração (predicador $\rightarrow$ predicação $\rightarrow$ proposição $\rightarrow$ oração), são considerados também aspectos semânticos (tipo de predicador e natureza de seus argumentos) e pragmáticos (ilocução, topicalização, focalização, dentre outros), o que reforça a impossibilidade de se descrever, satisfatoriamente, uma sintaxe "autônoma". Os desenvolvimentos da GF correspondem, atualmente, à teoria da Gramática Discursivo-Funcional (HENGEVELD; MACKENZIE, 2008) que, de certa forma, desenvolve algumas ideias já sugeridas por Dik (1997) acerca de uma gramática orientada pelo discurso. Contudo, embora compartilhem os mesmos pressupostos funcionalistas, são modelos diferentes de análise.

A Gramática Discursivo-Funcional (GDF), ao contrário da GF, organiza-se num modelo top-down de análise, partindo da intenção do falante (Componente Conceitual) para a realização das expressões linguísticas (Componente de Expressão). A unidade básica na GDF é o ato discursivo (unidade comunicativa) e não a oração (unidade morfossintática, como na GF), podendo compreender expressões linguísticas menores ou maiores que esta. Nesse modelo, a gramática é um componente que, no processo de interação verbal, não opera isoladamente, mas interage com outros três: Conceitual, Contextual e de Expressão (Figura 1):

\footnotetext{
No original: "NLU's do not speak in isolated sentences or clauses, but combine these into longer and more complex stretches for which we may use the general cover term "discourse". A discourse is more (much more) than an arbitrary sequence of clauses. Therefore, even if we had an optimal theory of the clause, this theory would still leave much to be desired when considered as a component in a wider theory of NLU'S communicative competence. Moreover, since clauses, in their internal structure, are sensitive to a variety of discourse factors, an "optimal" theory of (isolated) clause is simply impossible." (DIK, 1997, p.409).
} 
Figura 1 - Componentes relacionados à GDF

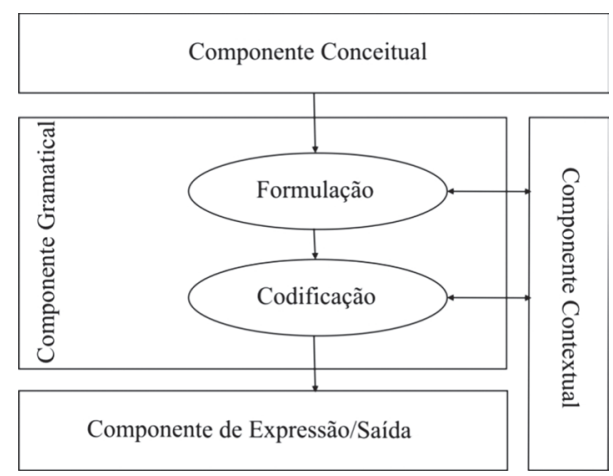

Fonte: Hengeveld e Mackenzie (2008, p.6).

O Componente Conceitual compreende as intenções comunicativas e as representações conceituais relevantes que serão transformadas em representações linguísticas. Segundo os autores, " [... e é a força motivadora por trás do Componente Gramatical como um todo."7 (HENGEVELD; MACKENZIE, 2008, p.7). Todo material cognitivo e ideacional, relevante para cada ato discursivo, situa-se nesse componente. O Componente Contextual guarda as informações e características da situação discursiva, tanto no que diz respeito ao discurso precedente e à situação imediata da interação, quanto às relações sociais entre os participantes (sexo, papel social etc.). Os processos de referenciação, o uso de reflexivos e as sequências narrativas, por exemplo, dependem da interação desse componente com o Gramatical. O Componente de Expressão gera a expressão acústica ou gráfica da informação fornecida pelo Componente Gramatical, que constitui o domínio específico da GDF. Todas as informações relacionadas ao conhecimento linguístico (lexicais, sintáticas, semânticas e pragmáticas) pertencem a este componente e são ativadas a partir das intenções do falante numa dada situação comunicativa ${ }^{8}$. O verbo "existir", por exemplo, é apresentado como um verbo intransitivo nas gramáticas tradicionais. No entanto, enunciados com esse verbo denotam a necessidade de informações complementares para o estabelecimento da referência, geralmente representadas por um sintagma adjetival (simples ou oracional) ou adverbial:

7 No original: "[The Conceptual Component] is the driving force behind the Grammatical Component as a whole." (HENGEVELD; MACKENZIE, 2008, p.7)

8 Os elementos de cada nível do Componente Gramatical (Interpessoal, Representacional, Morfossintático e Fonológico) serão discutidos à medida que forem necessários para a descrição das orações subordinadas substantivas estudadas. 
i) Existem pizzas. (?)

ii) Existem pizzas sem queijo.

iii) Existem pizzas exóticas.

iv) Existem pizzas que custam caro.

v) Existem pizzas na geladeira.

Pode-se dizer que existe uma "transitividade" nesses enunciados, como um todo (e não como uma característica do verbo), motivada pela situação de interação. O exemplo (i) não seria, certamente, a primeira frase de uma interação, mas possivelmente a segunda, em resposta a uma pergunta como "O que existe nessa geladeira?" $\rightarrow$ "Existem pizzas (nessa geladeira)". De (ii) a (v), por outro lado, têm-se enunciados que estabelecem, por si mesmos, uma referência a partir da informação que o falante quer transmitir ao ouvinte.

A descrição da língua a partir do uso, das intenções e das situações de interação possibilita a percepção de aspectos que, embora não sejam inerentes à estrutura/forma linguística, também participam de sua organização.

\section{Proposta: descrição de algumas orações subordinadas substantivas do ponto de vista interdiscursivo}

Em geral, os manuais de gramática abordam as orações subordinadas substantivas unicamente a partir da função sintática que exercem em relação ao predicador da oração principal, sendo a transitividade um fator fundamental. Para a descrição das construções complexas estudadas, foram selecionados outros critérios: (1) escolha do predicador da oração principal; (2) uso da forma reduzida ou desenvolvida da oração subordinada, procurando-se observar de que maneira as relações interdiscursivas motivam essas escolhas, produzindo diferentes sentidos. Considere-se, inicialmente, a escolha do predicador da oração principal:

(01) Eu prometo / que não contarei nada a ninguém.

(02) Ordeno / que todos enviem os documentos pedidos até amanhã.

(03) Os especialistas dizem / que boa alimentação deve ser acompanhada de exercícios.

(04) Acho / que todos esses alunos foram reprovados na avaliação.

(05) É importante / que todos participem desta reunião. 
Como se pode observar, o predicador codifica a ilocução (força ilocucionária) do ato discursivo, bem como aspectos subjetivos do enunciado que estão diretamente associados à relação interpessoal dos participantes. Em (01), temse uma promessa; em (02), uma ordem; em (03), a declaração de um conteúdo comunicado por terceiros; em (04), uma declaração cujo conteúdo é apresentado como suposto pelo enunciador; no exemplo (05), uma situação é avaliada como "importante" pelo falante que, no entanto, não se manifesta explicitamente no enunciado. O conteúdo dos enunciados, propriamente, se encontra na oração subordinada e, em termos informativos, poderia ser dito através de uma oração simples. Nos termos da GDF, o conteúdo comunicado corresponde àquilo que o falante deseja evocar em sua interação com o ouvinte; a oração principal, por sua vez, constitui um modificador desse conteúdo.

Percebe-se, dessa maneira, que a construção complexa é um recurso sintático que permite ao falante agregar outras "informações" ao enunciado, segundo suas intenções: seja se comprometendo (01 e 02), seja expressando a fonte de uma informação e garantindo sua confiabilidade (03), seja modalizando o enunciado, para não se comprometer (04 e 05).

Nos exemplos abaixo, retirados de jornais distintos, verificam-se diferentes posturas do enunciador diante de um mesmo fato, a partir da escolha do predicador da oração principal:

(06) ["Você só tem que ler a nota que nós distribuímos. Você vai perceber que a nota comunica que houve proposta do presidente Sarkozy para que houvesse avanço nas negociações e, por causa disso, nós decidimos recomeçar as negociações. É isso. Agora, como somos um país de muita liberdade de imprensa, e sobretudo de imaginação fértil das pessoas que fazem imprensa, cada um escreveu o que quis"], disse [o presidente Lula]. (FSP_1)

(07) Indagado sobre o assunto, Lula responsabilizou o que chamou de "imaginação fértil" da imprensa pela confusão. ["Como nós somos um país com muita liberdade de imprensa e, sobretudo, de imaginação fértil das pessoas que fazem imprensa, cada um escreveu o que quis"], ironizou [o presidente Lula]. (ESP_1)

Embora ambas as notícias se refiram a um mesmo acontecimento (a manifestação do presidente Lula acerca de um possível mal-entendido sobre a escolha dos caças para a FAB), no exemplo (06) há uma postura mais neutra do jornalista com a escolha do predicador "dizer"; em (07), o jornalista opta por explicitar o tom da fala reportada, com a escolha do verbo "ironizar".

Em relação à oração subordinada, como já dito, observou-se o uso de sua forma desenvolvida ou reduzida. Nas gramáticas tradicionais, essa diferença é tratada apenas em termos formais, sendo a oração desenvolvida introduzida por uma conjunção integrante (que, se), e a oração reduzida contendo o verbo no 
infinitivo ou no gerúndio. Bechara (2009, p.515) atribui essas diferentes escolhas a uma questão de estilo: "O emprego de reduzidas por desenvolvidas e vice-versa, quando feito com arte e bom gosto, permite ao escritor variados modos de tornar o estilo conciso, não acumulado de quês e outros transpositores, enfim, elegante." Contudo, uma ou outra forma pode significar diferentes status do evento expresso na oração subordinada:

(08) Eu o vi / sair/saindo.

(09) Eu vi / que ele saiu.

Em (08), o uso da oração reduzida expressa um estado-de-coisas testemunhado pelo falante (e o verbo "ver" tem seu sentido básico de percepção visual), ao passo que (09) mostra uma conclusão tirada a partir de alguma evidência (o verbo "ver", neste caso, expressa uma atividade mental). A escolha de uma ou outra forma depende tanto do contexto real (em que o falante apenas relata o que aconteceu) quanto da possível intenção de preservar sua face: mesmo num contexto em que tenha testemunhado alguém saindo (08), pode manifestar isso como uma inferência (09), para não se comprometer. No exemplo (10), em que se tem a introdução da voz do outro pelo Discurso Indireto, verifica-se que o uso da forma reduzida sugere certa dúvida do jornalista (o enunciador do discurso principal) quanto ao conteúdo expresso na oração subordinada:

(10) Jobim diz [desconhecer proposta da Suécia], que ofereceria os Gripen pela metade do preço dos franceses Rafale. (ESP_2)

(10') Jobim diz [que desconhece proposta da Suécia],...

Nesse exemplo, embora a oração reduzida seja mais integrada à oração principal do ponto de vista sintático, do ponto de vista semântico parece ser mais frouxa, deixando espaço para que aquele que reporta o discurso do outro expresse certa dúvida quanto ao conteúdo deste discurso (Jobim diz desconhecer, [mas eu, jornalista, não acredito]). O contrário se verifica em $\left(10^{\prime}\right)$, em que a forma desenvolvida parece sugerir a veracidade do conteúdo expresso no enunciado.

Como se observa a partir dessas reflexões - que partem dos aspectos formais presentes nos manuais de gramática - é possível dizer que a abordagem tradicional da gramática deixa a desejar na descrição que faz das orações subordinadas substantivas, uma vez que se atém unicamente à descrição de aspectos da estrutura da língua. Quanto à funcionalidade dessas construções nos contextos em que foram estudadas, verifica-se que constituem práticas discursivas de extrema importância na comunicação, tal como se discute a seguir a partir de cada um dos predicadores estudados. 


\section{a) Os verbos dicendi e a introdução da voz do outro e da própria voz}

Como apresentado na Tabela 2, os verbos dicendi correspondem ao tipo de predicador mais frequente nas orações substantivas do corpus e, basicamente, servem para introduzir a voz do outro no discurso. Segundo Neves (2000, p.48, grifo do autor), os verbos dicendi, ou verbos de elocução, "são verbos de ação cujo complemento direto é o conteúdo do que se diz". Ao trazer a voz do outro para seu texto, o falante reforça a confiabilidade da informação dada, ao mesmo tempo em que assume um menor comprometimento com ela, sendo mais imparcial e preservando sua face. Em relação aos textos jornalísticos (notícias e artigos de opinião) e aos textos de divulgação científica, pode-se dizer que essas são as principais funções dessa construção:

(11) O presidente do Ibama prometeu, além disso, aumentar o rigor da fiscalização dos carregamentos e criticou as empresas envolvidas na irregularidade, cujos nomes permanecem no sigilo. "Isso não é empresa, é um bando de urubu", afirmou. (ESP_3)

(12) "Uma pessoa vegetariana, que come mais fibras que a média, absorve calorias de forma diferente", afirmou a nutricionista Helena Simonard Loureiro, da PUCPR. "Parte os nutrientes pode passar muito rápido pelo intestino e, se não houver absorção, também não há calorias". (GAL_1)

Nos textos literários, ao contrário, a inserção da voz do outro - no caso, dos personagens - é um recurso que possibilita ao narrador dar mais expressividade e verossimilhança à narrativa, recriando situações de interação entre os personagens:

(13) Os juazeiros aproximaram-se, recuaram, sumiram-se. O menino mais velho pôs-se a chorar, sentou-se no chão.

- [Anda, condenado do diabo], gritou-lhe o pai. (VS)

(14) Capitu segredou-me [que a escrava desconfiara], e [ia talvez contar às outras]. Novamente me intimou [que ficasse], e retirou-se; eu deixei-me estar parado, agarrado ao chão. (DC)

De acordo com a GDF, a reportatividade é uma estratégia que se codifica nas relações interpessoais, uma vez que um discurso (ato de fala) funciona como um argumento de verbo dicendi (como gritar, segredar e intimar). Este, como já dito, atua como um modificador do discurso citado (o conteúdo comunicado, propriamente), a partir do qual o falante indica a fonte dessa informação (a 
indicação da fonte de uma informação ou do modo como o falante obteve essa informação configura o estatuto evidencial do enunciado). ${ }^{9}$

Além da introdução da voz do outro, também foram encontrados exemplos em que o falante introduz a própria voz ao seu discurso:

(15) Segundo cientistas da Universidade de Michigan, os benefícios começam a aparecer depois de 12 dias. Faça os exercícios abaixo. E lembre-se de outra coisa: "Quando me perguntam o que fazer para melhorar a memória, sempre respondo: [ler. Não há nada melhor"], afirma o neurologista Ivan Izquierdo. (SI_1)

(16) Costumo dizer [que a droga socializa o crime]. Hoje, você tem pessoas de classe média e da classe alta envolvidas com o tráfico - e não apenas com o uso de drogas. (FSP_2)

(17) Já disse a você [que quero mudar de vida... viver bem os irmãos, ser um sujeito decente]. (CD_1)

Como se pode observar em (15), (16) e (17), ao trazer a própria voz ao seu discurso, o falante não apenas reforça o comprometimento com o que diz como também mostra a incidência desse dizer, que nos exemplos acima se codifica nas expressões linguísticas sempre (15), costumo (16) e já (17). Foram encontradas também situações em que o enunciador insere a própria voz em tempo futuro, como se estivesse planejando/prevendo uma enunciação:

(18) Sabemos que, a partir de agora, o máximo que podemos jogar na atmosfera para que a temperatura não aumente mais de $2^{\circ} \mathrm{C}$ em relação ao período pré-industrial são 500 bilhões de toneladas de carbono. Nós já soltamos 500 bilhões de toneladas e agora temos esse mesmo valor, mas agora estamos jogando 10 bilhões por ano. Se esse ritmo aumentar, daqui a 40 anos diremos [que ninguém mais poderá jogar uma molécula sequer]. (ESP_4).

A integração da própria voz pode significar, dependendo da escolha do predicador da oração principal, diferentes relações entre os interlocutores, como se observa em (19) e (20):

(19) - Olhe, prometo outra coisa; prometo [que há de batizar o meu primeiro filho]. (DC)

\footnotetext{
Segundo Maingueneau (1997), retomado em Fiorin (1999), os verbos dicendi podem ser classificados em descritivos e avaliativos. Com exceção do verbo "dizer", que seria neutro em relação a estes dois grupos, os verbos que introduzem o discurso do outro "veiculam diversos tipos de pressupostos" (MAINGUENEAU, 1997, p.88). Dentre os descritivos, têm-se os que (1) situam o discurso citado em uma cronologia discursiva (repetir, concluir, etc.); (2) explicitam a força ilocucionária do ato enunciativo (prometer, pedir e semelhantes); (3) indicam o tipo de discurso citado (relatar, argumentar, dentre outros) e (4) especificam o modo de realização fônica do enunciado (murmurar, gritar, sussurrar e outros). No que diz respeito aos avaliativos, implicam o julgamento (a) positivo (explicar, analisar, afirmar, etc.) ou (b) negativo (jurar, justificar, ironizar, dentre outros) do enunciador do discurso citado e do próprio discurso.
} 
(20) D. Sancha, peço-lhe [que não leia este livro]; ou, se o houver lido até aqui, abandone o resto. (DC)

Em (19), a relação que se estabelece entre os interlocutores seria comprometida caso o predicador fosse um verbo neutro, como "dizer" (...digo que há de batizar o meu primeiro filho); ao utilizar "prometer", o falante estabelece um compromisso com seu interlocutor, constituindo um ato de fala performativo. $\mathrm{O}$ exemplo (20) ilustra, por outro lado, a busca pela preservação da face: ao qualificar seu dizer como um "pedido", o enunciador se livra do autoritarismo que the conferiria o enunciado dito diretamente (...não leia este livro). Embora não se tenha, nesses casos, a re-enunciação de enunciados já ditos (uso prototípico dos verbos dicendi), tem-se a introdução de enunciados que se qualificam explicitamente como atos de fala em função do verbo predicador da construção completiva, ou seja, dos verbos que os introduzem no discurso presente.

As construções complexas predicadas por verbos dicendi constituem um recurso linguístico bastante frequente para o "empacotamento" da voz do outro ou da própria voz ao discurso do falante, e codificam diversos aspectos subjetivos associados às suas intenções. A seguir, serão considerados aspectos relacionados aos verbos de atividade mental.

\section{b) Os verbos de atividade mental e a modalização do enunciado}

O segundo tipo de predicador mais frequente nas orações complexas estudadas foram os verbos de atividade mental (achar, acreditar, admitir, crer, descobrir, pensar, entre outros). Segundo Hengeveld e Mackenzie (2008), esses verbos podem ter, como segundo argumento, uma proposição (21) ou um estado-de-coisas (22):

(21) Tenho profunda simpatia pela meditação, embora não a pratique. Não acho [que a ideia de uma atividade introspectiva silenciadora da consciência seja incompatível com ciência, ao contrário]. (FSP_2)

(22) No final do século 19, um químico americano descobriu [que era possível contar a quantidade de energia dos alimentos]. (GAL_1)

Um estado-de-coisas é um evento ou situação possível de ser percebido no mundo real ou em um mundo imaginário. As proposições, por outro lado, correspondem a hipóteses e suposições, visto que resultam da concepção do falante acerca de um determinado contexto. Para Hengeveld e Mackenzie (2008), na camada da proposição se situam elementos que remetem tanto à modalidade epistêmica, que explicita o grau de comprometimento do falante em relação ao conteúdo proposicional (certeza, dúvida, [des]crença), quanto à modalidade 
evidencial, que se refere à especificação de como o falante chegou a esse conteúdo (se por uma evidência direta, um relato ou uma inferência). De qualquer forma, qualquer que seja a natureza dessa informação (epistêmica ou evidencial), ela poderá ser codificada na oração principal, pela escolha do predicador (achar, descobrir, pensar, saber), ou na forma da oração subordinada - desenvolvida ou reduzida (conferir exemplos 08 e 09). Nos dados do corpus, essa codificação foi mais recorrente pela escolha do predicador da oração principal.

Além disso, também a maneira como o sujeito da oração principal é expresso denota diferentes graus de comprometimento do falante com a informação dada. Vejamos:

(23) Mas eu creio [que Capitu olhava para dentro de si mesma], enquanto que eu fitava deveras o chão, o roído as fendas... (DC)

(24) Todos, menos os ingênuos, sabem [que, assim como não existe meia gravidez, também não há meia dependência]. É raro encontrar um consumidor ocasional. (FSP_2)

(25) Acredita-se [que seja saudável perder 5 a 10\% do seu peso em 6 meses] - para alguém com 60 quilos, no máximo 1 quilo por mês. (SI_2)

(26) Sabia-se confusamente [que a doida tinha sido moça igual às outras no seu tempo remoto]. (CD_2)

Em (23), o falante assume o comprometimento que tem com uma crença que é sua ("eu creio"); no exemplo (24), ao contrário, divide a responsabilidade pela informação com "os outros", inclusive com o interlocutor ("Todos sabem"). Em (25) e (26), por fim, a não expressão da fonte da informação sugere um menor comprometimento do falante com o conteúdo do enunciado ("Acredita-se", "Sabia-se"). Embora a informação seja um conhecimento compartilhado, não há uma fonte específica responsável por ela. Esse mecanismo funciona, assim, como uma estratégia de preservação da face.

Outro aspecto relacionado ao uso das construções complexas com verbos de atividade mental é a modalização, com a intenção de atenuar o enunciado, tornando-o mais polido: o mesmo conteúdo de "Ela deve estudar mais, senão não vai passar no Vestibular", incisivo e áspero, pode ser expresso como "Acho [que ela deveria estudar mais], para poder passar no Vestibular", de maneira a evitar uma possível reação negativa do ouvinte.

Com essas construções, o falante também pode motivar seu interlocutor a repensar e criar situações, orientando-o na interação conforme seus interesses, o que se configura como uma estratégia argumentativa, como nos exemplos (27) e (28): 
(27)

- Prima Justina, a senhora era capaz de uma coisa?

- De quê?

- Era capaz de... Suponha [que eu não gostasse de ser padre]... A senhora podia pedir a mamãe...

- Isso não, atalhou prontamente; prima Glória tem este negócio firme na cabeça, e não há nada no mundo que a faça mudar de resolução; só o tempo. (DC)

(28) Mas nem é preciso crimes ou sessões de hipnose para colocar nossas memórias em xeque. Imagine [acordar certo dia] e [descobrir que parte das suas lembranças é pura imaginação]. Isso porque a memória não é um registro da realidade - é uma interpretação construída pela mente. (SI_1)

A partir das orações subordinadas substantivas predicadas por verbos de atividade mental, foi possível perceber que se relacionam, essencialmente, à manifestação de um maior ou menor grau de comprometimento do falante com a informação dada, no sentido de o enunciador (a) ser ou não sua fonte e (b) expressar certeza, dúvida ou (des)crença; essas construções também podem participar da construção da argumentação, levando o interlocutor a supor situações que, de alguma maneira, facilitem a interação.

Na próxima seção serão discutidas as construções cujo predicador é a expressão predicativa "ser + adjetivo", que seleciona como único argumento uma oração subordinada substantiva Subjetiva.

\section{c) A construção "ser + adjetivo" e a impessoalização do enunciado}

A própria natureza predicativa dessa construção pressupõe, por si só, a presença da subjetividade do falante, tento em vista sua função avaliativa. A partir da escolha do adjetivo é possível perceber a maneira como ele percebe e julga o mundo ao seu redor. Embora essa construção expresse uma avaliação do enunciador acerca de um estado-de-coisas ou de uma proposição, é interessante observar que ocorre o apagamento daquele que enuncia, e é a oração subordinada que assume a posição de sujeito do enunciado.

Essa impessoalização favorece um maior distanciamento do falante em relação ao que diz, embora lhe permita dizer, manifestar-se.

(29) É preciso também [alertar as crianças nas escolas] para que saibam como se defender e tenham canais seguros para fazê-lo, sem risco de retaliações ainda piores. (FSP_3) 
(30) É fácil, porém, [constatar que os 70 mil óbitos não estão em linha com as cifras mais comumente empregadas]. A OMS (Organização Mundial da Saúde), por exemplo, estima que a influenza comum provoque entre 250 mil e 500 mil mortes anuais em todo o planeta. Ora, se o Brasil, sozinho, contabiliza 70 mil, ou bem o país apresenta uma letalidade incrivelmente maior do que a média mundial ou a nossa população teria de corresponder a algo entre 14\% e 28\% do total de habitantes da terra. Como nenhuma dessas hipóteses parece verossímil (somos menos de 3\%), é melhor [desconfiar dos números]. (FSP_4)

Em (29), o falante faz referência à necessidade de um estado-de-coisas (alertar as crianças), segundo a concepção que tem acerca da violência infantil. O uso da oração reduzida de infinitivo coloca esse estado-de-coisas como um dever de todos, visto que não se tem referência a um sujeito específico. O exemplo (30) mostra uma situação em que o falante avalia um estado-de-coisas e traz, também, as evidências que lhe permitiram caracterizá-lo como sendo "fácil" (é fácil constatar $\mathbf{X}$ a partir de $\mathbf{Y}$ ); dessa maneira, aponta para a responsabilidade de qualquer pessoa fazer tal constatação e, de certa maneira, preserva sua face. No segundo caso, o falante faz uma sugestão ao seu interlocutor, tendo em vista os argumentos já apresentados em seu discurso, na intenção e adverti-lo a "desconfiar" de dados possivelmente errôneos.

Embora essas construções, assim como as predicadas por verbos de atividade mental, revelem opiniões, crenças e valores do falante acerca de um evento (estado-de-coisas) ou um fato possível (proposição), é importante ressaltar que são menos "comprometedoras", pois são impessoais.

Essas diferentes construções sintáticas disponíveis aos falantes são, na verdade, motivadas pelas necessidades comunicativas com que se deparam nas situações de interação, constituindo-se mecanismos de "empacotamento" da informação. Acredita-se que a descrição proposta para essas construções, com base na sua funcionalidade e em aspectos interdiscursivos, pode ser levada para a sala de aula, a fim de fazer o aluno refletir sobre usos comuns ao seu próprio cotidiano e de grande importância em quaisquer situações comunicativas. É dessa perspectiva que se pode dizer que a sintaxe constitui o eixo da textualidade, uma vez que codifica (juntamente com o léxico) a intenção do falante, e é a partir da organização do enunciado que o ouvinte procurará compreender essa intenção.

\section{Adaptações que a língua sofre em função de necessidades comunicativas}

Observando-se as diferentes funções a que servem as orações estudadas, bem como a interação de diferentes processos no uso linguístico, de um modo geral, é 
possível argumentar em favor de ser a língua - de fato - um sistema adaptativo complexo. Segundo Bybee (2010, p.7),

[...] uma consequência de ver a língua como um sistema adaptativo complexo e sua estrutura como emergente (Lindblom et al. 1984, Hopper 1987) é focar nossa atenção não muito na estrutura linguística em si, mas nos processos que a criam (Verhagen 2002). Pesquisando os processos de domínio geral, não apenas diminuímos a busca por processos específicos da língua, como também a situamos dentro de um contexto maior do comportamento humano. ${ }^{10}$

Para Beckner et al. (2009), considerar a língua como um sistema adaptativo complexo envolve quatro pressupostos básicos:

- o sistema funciona a partir da interação de múltiplos agentes (indivíduo/ comunidade), o que sugere a presença da subjetividade dos seus usuários;

- o sistema é adaptativo, o que é contrário à ideia de uma estrutura estável, tal como pressuposta por abordagens formais e mesmo pelas gramáticas tradicionais;

- o comportamento dos usuários é consequência de fatores que variam de percepções a motivações sociais (como se pode observar pelos princípios do cognitivismo e do funcionalismo);

- a estrutura do sistema - a língua - emerge de padrões inter-relacionados da experiência, interação social e mecanismos cognitivos, o que corrobora a participação de elementos não linguísticos em sua constituição e, especialmente, a necessidade de considerá-los na observação e descrição desse sistema.

A interação dos vários elementos que participam da constituição e do uso da língua (conceituais, cognitivos, culturais, contextuais, subjetivos e linguísticos) mostra sua dinamicidade e revela sua natureza adaptativa, uma vez que esses elementos também estão sujeitos a variações e mudanças (o que determina as especificidades das línguas). Contudo, é importante ressaltar que, apesar de sua variabilidade, a língua não deixa de ser um sistema estruturado: "A língua é uma das formas mais sistemáticas e complexas do comportamento humano." (BYBEE, 2010$, p.6) $)^{11}$.

As construções e expressões linguísticas são pareamentos entre forma e significado, e isso inclui a pragmática. O contexto é determinado social e

10 No original: "[...] a consequence of viewing language as a complex adaptative system and linguistic structure as emergent (Lindblom et al. 1984, Hopper 1987) is that it focuses our attention not so much on linguistic structure itself, as on the processes that create it (Verhagen 2002). By searching for domain-general processes, we not only narrow the search for processes specific to language, but we also situate language within the larger context of human behavior." (BYBEE, 2010, p.7).

11 No original: "Language is one of the most systematic and complex forms of human behavior" (BYBEE, 2010, p.6). 
cognitivamente, e tudo constitui esse sistema complexo, dinâmico e adaptativo que é a língua. Segundo Bybee (2010), não são apenas porções idiomáticas que mostram a forte interação entre itens lexicais específicos e construções gramaticais. As orações completivas - uma estrutura sintática geral - assumem diferentes valores (semânticos e pragmáticos) em função da escolha do predicador da oração principal, como de fato se pôde observar a partir das orações predicadas por verbos dicendi, por verbos de atividade mental e pelo predicador "ser + adjetivo", aqui descritas. Para Bybee (2010, p.79), "[...] os itens lexicais que ocorrem numa construção contribuem para seu significado e ajudam a determinar sua função e distribuição no discurso." "12; daí, pode-se perceber a importante relação entre léxico e gramática.

Considerando-se as orações subordinadas substantivas estudadas, pode-se dizer que surgiram da necessidade básica de os seres humanos preencherem uma posição argumental com o relato de um evento e não com um item lexical denominando um ser. Observem-se as orações abaixo, cada uma delas comparada a construções em que o complemento é um item lexical:

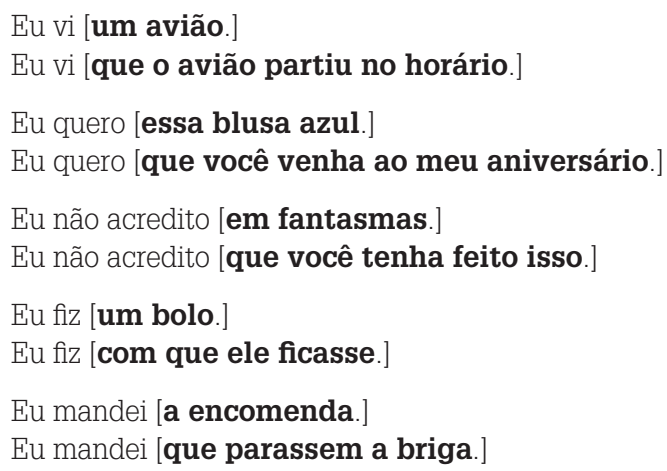

Em cada situação, da referência a um indivíduo/entidade passa-se à referência a um evento/situação, utilizando-se para isso uma oração subordinada substantiva; tem-se um argumento verbal que é, semanticamente, um evento. Tal é a origem primária das orações subordinadas substantivas, que corresponde a uma primeira adaptação do sistema (no que diz respeito a essa construção sintática) diante de uma necessidade comunicativa do falante.

Nas orações estudadas, também é possível pensar em algumas adaptações do sistema linguístico, quanto à funcionalidade dessas construções. Os verbos dicendi - também chamados de verbos de elocução - têm a função básica de introduzir a voz do outro (podendo o falante integrar - ou não - a opinião desse

12 No original: "The lexical items that occur in a construction contribute to the meaning of the construction and help to determine function and distribution in discourse." (BYBEE, 2010, p.79). 
outro ao seu discurso). Como visto, porém, não raras vezes o falante adapta alguns desses verbos para introduzir também a própria voz ao seu discurso, retomando ou prevendo outra enunciação sua. O que poderia parecer redundante é, na verdade, uma estratégia criada pelo usuário para enfatizar ("É por isso que eu digo sempre que [a franqueza é fundamental no diálogo.]") ou modalizar ("Sugiro que [você não chegue atrasado novamente.]") uma opinião ou um ato de fala.

Os verbos de atividade mental servem para expressar, basicamente, o conhecimento que o falante tem de uma determinada situação, numa escala que varia entre certeza e dúvida, em virtude da maneira como o enunciador chegou à informação asseverada. No entanto, o português não é uma língua em que a indicação da fonte da informação (evidencialidade) é obrigatória; assim, a opção por expressá-la revela uma estratégia do falante para preservar sua face, diminuindo seu comprometimento com o que assevera ("Acho que [ela já saiu.]") ou modalizando um ato de fala ("Acredito que [você deva sair agora."]); por outro lado, o falante pode também assumir a responsabilidade pela informação, expressando maior comprometimento seu e dando maior confiabilidade ao enunciado ("Sei que [ela entregou o trabalho."]).

O predicador "ser + adjetivo", por fim, revela uma avaliação do falante acerca de um evento. Contudo, essa construção impessoaliza o enunciado, promovendo maior distanciamento do enunciador: "Acho interessante que [reveja o trabalho.]" $\rightarrow$ "É interessante que [reveja o trabalho.]". No primeiro caso, a opinião - necessariamente do falante - é explicitada; no segundo, a avaliação é apresentada de maneira objetiva, não associada a nenhum indivíduo expressamente. O apagamento do sujeito experienciador é uma adaptação motivada pela subjetividade do falante e pela intenção comunicativa que tem de ocultar essa subjetividade. Segundo Verhagen (2005), é uma perspectivização impessoal do enunciado. Para o autor, as construções completivas permeiam o domínio intersubjetivo da interação entre falante e ouvinte, em que as orações principais codificam aspectos desse domínio, e as orações subordinadas substantivas permeiam o domínio objetivo (em que se situam os objetos conceptualizados).

Todas essas adaptações observadas a partir do uso dessas construções são determinadas por elementos interdiscursivos. Segundo Bybee (2010), as motivações da direção à qual um sistema adaptativo complexo evolui são chamadas de atratores. No caso da língua, diversos elementos podem se configurar como atratores, sendo inclusive observados de maneira semelhante em diversas línguas. Abreu (2010) aponta como alguns atratores linguísticos o sentido (sendo esse o principal, pois a função básica da linguagem humana é a comunicação), a economia, a tipologia, a iconicidade, a contiguidade 
e a sociabilidade. A contiguidade, por exemplo, é um atrator que promove, numa relação sintagmática, a associação conceptual de palavras próximas e a consequente representação do conceito por apenas uma delas, como: telefone celular $\rightarrow$ celular; pessoas jovens $\rightarrow$ jovens. Isso permite a ação de outro atrator, a economia, também presente na redução de palavras: fotografia $\rightarrow$ foto; notebook $\rightarrow$ note.

O principal atrator associado às adaptações verificadas no uso das orações estudadas é a sociabilidade, em que o enunciador busca preservar sua face, modalizando os enunciados, ou busca garantir a confiabilidade da informação asseverada, indicando sua fonte. A intenção do falante faz parte de um contexto em que a expressão linguística deve servir também como mediadora das relações sociais entre os usuários, e não apenas para transmitir uma informação. Este contexto, também, atua como um atrator de novos arranjos e usos da língua, inclusive os domínios e gêneros discursivos relacionados à situação comunicativa.

Nesse sentido, também o gênero textual atua como um atrator na organização e no uso das orações substantivas, tendo em vista a predominância de certas construções em determinados gêneros. Em relação aos verbos dicendi, por exemplo, nos textos literários observou-se a maior frequência de orações subordinadas justapostas à oração principal, o que caracteriza o Discurso Direto usado para construir diálogos entre os personagens; nos textos de divulgação científica, a justaposição das orações também é recorrente, mas a finalidade é garantir a imparcialidade e a confiabilidade da informação a partir da introdução direta da voz do outro (uma autoridade no assunto); nos textos jornalísticos, por outro lado, predomina o uso do Discurso Indireto, que tende a ser mais conciso (característica essencial a esse domínio discursivo).

Em termos pragmáticos, as orações estudadas constituem estratégias pelas quais o enunciador escolhe maneiras de "empacotar" a informação que deseja fornecer ao seu interlocutor, o que está de acordo com a proposta de Verhagen (2005), que considera que a função primária da oração principal em uma construção completiva é codificar a perspectiva do falante em relação à conceptualização do que é expresso na oração subordinada (completiva).

Rosa (1990, 1992), ao propor uma classificação dos elementos linguísticos que atuam como marcadores de atenuação, atribui-lhes a função de evitar uma postura assertiva e autoritária do falante. Dentre as palavras e expressões que marcam a impessoalização, as construções com "É possível que", "É bom que", "Diz-se que", "Sabe-se que" são alguns exemplos de marcadores de distanciamento. As construções com verbos de atividade mental constituem, dessa perspectiva, marcadores de opinião, que revelam o conhecimento e o comprometimento do falante em relação ao que diz. 
No que diz respeito à complexidade do sistema linguístico, pôde-se verificar a interação de vários fatores, de diferentes naturezas, no uso das orações subordinadas substantivas, todos se manifestando equilibradamente (o que é essencial a um sistema complexo). Quanto à capacidade de adaptação, que pressupõe mudanças, não se observaram propriamente mudanças estruturais nas orações estudadas, uma vez que se procedeu a um estudo sincrônico. No entanto, foram constatados vários usos e funcionalidades dessas orações, em diferentes contextos, o que demonstra adaptações de natureza pragmática (lembrando que as adaptações podem ocorrer em todos os níveis do sistema). Nesse sentido, este trabalho corrobora a ideia de se pensar a língua como um sistema adaptativo complexo, e não como um sistema estável.

Com base nessa discussão, torna-se difícil imaginar as aulas de gramática ainda baseadas apenas no que propõem os manuais tradicionais, cuja concepção de língua é, basicamente, um sistema estável e autônomo. É necessário repensar o ensino da gramática, considerando-se todos os elementos que fazem parte do funcionamento da língua e estão envolvidos no seu uso.

\section{Considerações finais}

A descrição que se apresentou das orações subordinadas substantivas Objetivas Diretas (predicadas por verbos dicendi e por verbos de atividade mental) e Subjetivas (predicadas pela expressão "ser + adjetivo") a partir de aspectos interdiscursivos - relacionados à interação entre falante e ouvinte - permite-nos afirmar que as diferentes possibilidades de organização e uso dessas construções são motivadas, em grande parte, pelas intenções do falante ${ }^{13}$, as quais se codificam na sintaxe do enunciado (escolha do predicador, uso da forma desenvolvida ou reduzida etc.). Acredita-se que o ensino da sintaxe a partir da funcionalidade que essas orações assumem em diferentes situações comunicativas pode, efetivamente, desenvolver as habilidades linguísticas dos alunos, tanto em termos de compreensão quanto de produção de textos, uma vez que possibilita a reflexão também dos aspectos semânticos e pragmáticos associados à forma linguística. Espera-se ter contribuído, dessa maneira, para um melhor tratamento do processo de subordinação substantiva e, consequentemente, para a prática pedagógica do ensino de gramática.

13 Os fatores de natureza discursiva atuam em consonância com o próprio sistema gramatical das línguas que, também, possuem restrições e motivações de natureza tipológica, inerentes à estrutura linguística: em uma construção completiva que tenha como predicador um verbo volitivo (querer, desejar), se houver identidade de participantes entre as orações principal e subordinada, a forma infinitiva será obrigatória na oração subordinada (Eu quero terminar o trabalho hoje; João quer terminar o trabalho hoje). No entanto, é importante ressaltar que questões dessa natureza geralmente são consideradas a partir de uma abordagem tradicional da gramática, uma vez que privilegiam a forma linguística. O que se pretendeu a partir da discussão aqui proposta foi mostrar que, além destes, outros fatores - de natureza extralinguística - participam da organização e funcionamento da língua, e devem também ser levados em conta no ensino. 


\section{Agradecimento}

Agradeço ao Prof. Dr. Antônio Suárez Abreu, pelas ricas sugestões e pela leitura atenciosa deste texto.

SPERANÇA-CRISCUOLO, A. C. Syntax of complex clauses in Portuguese: a proposal of description and teaching. Alfa, São Paulo, v.57, n.2, p.495-518, 2013.

- ABSTRACT: In this paper, motivated by problems related to grammar teaching, we propose a description of some noun subordinate clauses from an interdiscursive perspective. Based on the principles of the Functional Discourse Grammar theory (HENGEVELD; MACKENZIE, 2008), we observed some subjective aspects encoded by these syntactic constructions, motivated by the Speaker's communicative intentions. In pragmatic terms, the complement clauses we studied correspond to the Speaker's strategies to demonstrate his commitment degree with what he's saying, protecting his/her face, and also assuring the information's reliability; in linguistic terms, they show the language suffers some adaptations (BYBEE, 2010) to serve the Speaker's communicative needs. We believe that the focus in the functionality of these constructions can make its teaching richer and more efficient, and so the students' language performance.

- KEYWORDS: Syntax. Complex clause. Functional approach. Complexity. Description. Teaching.

\section{REFERÊNCIAS}

ABREU,A. S. Linguística Cognitiva: uma visão geral e aplicada. Cotia:Ateliê, 2010. BECHARA, E. Moderna Gramática Portuguesa. 37.ed. Rio de Janeiro: Nova Fronteira, 2009.

BECKNER, C. et al. Language is a complex adaptative system: position paper. Language Learning, Michigan, v.59, supplement 1, p.1-26, 2009. Disponível em: $<$ http://cnl.psych.cornell.edu/pubs/2009-LACAS-pos-LL.pdf >. Acesso em: 13 mar. 2011.

BRASIL. Secretaria de Educação Fundamental. Parâmetros curriculares nacionais: terceiro e quarto ciclos do ensino fundamental: língua portuguesa. Brasília: MEC/ SEF, 1998. Disponível em:<http://portal.mec.gov.br/seb/arquivos/pdf/portugues. pdf $>$. Acesso em: 01 jun. 2009.

Parâmetros curriculares nacionais: língua portuguesa ( $1^{\mathrm{a}}$ a $4^{\mathrm{a}}$ séries). Brasília: MEC/SEF, 1997. Disponível em: <http://portal.mec.gov.br/seb/arquivos/ pdf/livro02.pdf>. Acesso em: 01 jun. 2009.

BYBEE, J. Language, usage and cognition. Cambridge: Cambridge University Press, 2010.

DIK, S. The Theory of Functional Grammar. complex and derived constructions. Berlin: Mouton de Gruyter, 1997. pt.2. 
FIORIN, J. L. As astúcias da enunciação. 2.ed. São Paulo: Ática, 1999.

GERALDI, J. W. Portos de passagem. São Paulo: Martins Fontes, 1993.

HENGEVELD, K.; MACKENZIE, L. Functional Discourse Grammar: a typologicallybased theory of language structure. Oxford: Oxford University Press, 2008.

MAINGUENEAU, D. Novas tendências em análise do discurso. 3.ed. Campinas: Pontes: ed. da UNICAMP, 1997.

NEVES, M. H. M. Gramática de usos do português. São Paulo: Ed. da UNESP, 2000.

ROSA, M. M. Marcadores de atenuação. São Paulo: Contexto, 1992.

Marcadores de atenuação na linguagem falada culta da cidade de São Paulo (NURC-SP). 1990. 135f. Dissertação (Mestrado em Filologia e Língua Portuguesa) - Faculdade de Filosofia, Letras e Ciências Humanas, Universidade de São Paulo, São Paulo, 1990.

VERHAGEN,A. Constructions of intersubjectivity. discourse, syntax and cognition. New York: Oxford University Press, 2005.

\section{Anexo (Referências dos exemplos citados)}

ESP_1: REUTERS. Lula diz que escolha de novo caça da FAB está indefinida. O Estado de S. Paulo, São Paulo, 16 set. 2009. Disponível em: <http://www. estadao.com.br/noticias/geral,lula-diz-que-escolha-de-novo-caca-da-fab-estaindefinida,436180,0.htm>. Acesso em: 17 set. 2009.

ESP_2: BARSETTI, S. Jobim diz desconhecer proposta da Suécia, que ofereceria os Gripen pela metade do preço dos franceses Rafale. O Estado de S. Paulo, São Paulo, 19 set. 2009. Disponível em: <http://www.estadao.com.br/ estadaodehoje/20090919/not_imp437653,0.php>. Acesso em: 19 set. 2009.

ESP_3: MURAKAWA , F. Presidente do Ibama exige 'repatriação' de lixo inglês. $O$ Estado de S. Paulo, São Paulo, 16 jul. 2009. Disponível em: <http://www.estadao. com.br/geral/not_ger403910,0.htm>. Acesso em: 04 ago. 2009.

ESP_4: BALAZINA, A. "País tem de liderar revolução tropical". Pesquisador defende que Brasil pare de focar o Bric e crie, em Copenhague, um grupo de nações com floresta tropical. O Estado de S. Paulo, São Paulo, 25 out. 2009. Disponível em: <http://www.estadao.com.br/estadaodehoje/20091025/not_imp456002,0. php>. Acesso em: 25 out. 2009. 
FSP_1: FALCÃO, M. Lula diz que compra de caças não pode ser no "chutômetro". Folha de S. Paulo, São Paulo, 16 set. 2009. Disponível em: <http://www1.folha.uol. com.br/folha/brasil/ult96u624870.shtml>. Acesso em: 17 set. 2009.

FSP_2: PERON, H. O que pode fazer diferença num jogo de futebol. Folha de $S$. Paulo, São Paulo, 10 nov. 2009. Disponível em: <http://www1.folha.uol.com.br/ folha/colunas/futebolnarede/ult868u650279.shtml>. Acesso em: 26 jan. 2010.

FSP_3: CANTANHÊDE, E. Uma reflexão. Folha de S. Paulo, São Paulo, 24 jun. 2009. Disponível em: <http://www1.folha.uol.com.br/folha/pensata/elianecantanhede/ ult681u585646.shtml>. Acesso em: 28 jul. 2009.

FSP_4: SCHWARTSMAN, H. Desconfie dos números. Folha de S. Paulo, São Paulo, 6 ago. 2009. Disponível em: <http://www1.folha.uol.com.br/folha/pensata/ helioschwartsman/ult510u605495.shtml>. Acesso em: 20 set. 2009.

GAL_1: LOIOLA, R. Cuidado: as calorias enganam. Galileu, Rio de Janeiro, ed.218, set. 2009. Disponível em: <http://revistagalileu.globo.com/Revista/ Common/0, EMI111996-17579,00-CUIDADO+AS+CALORIAS+ENGANAM.html>. Acesso em: 10 out. 2009.

SI_1: BLANCO, G. Memória - Parte 2 - Toda a informação do universo. Superinteressante, São Paulo, ed.264, abr. 2009. Disponivel em: <http://super. abril.com.br/ciencia/memoria-parte-2-toda-informacao-universo-617875.shtml>. Acesso em: 25 maio 2009.

SI_2: CARMELLO, C. Dieta sem segredo. Superinteressante, São Paulo, ed.265, maio 2009. Disponível em: <http://super.abril.com.br/alimentacao/dietasegredo-619322.shtml>. Acesso em: 20 maio 2009.

CD_1:ANDRADE, C. D. A salvação da alma. In: Contos de aprendiz. 53.ed. Rio de Janeiro: Record, 2008.

CD_2: ANDRADE, C. D. A doida. In: Contos de aprendiz. 53.ed. Rio de Janeiro: Record, 2008.

DC: ASSIS, M. Dom Casmurro. Rio de Janeiro: Globo Ed., 2008. Disponível em: $<$ http://www.dominiopublico.gov.br/download/texto/bv00180a.pdf>. Acesso em: 28 jul. 2009.

VS: RAMOS, G. Vidas Secas. 107.ed. Rio de Janeiro: Record, 2008.

Recebido em outubro de 2011

Aprovado em novembro de 2012 